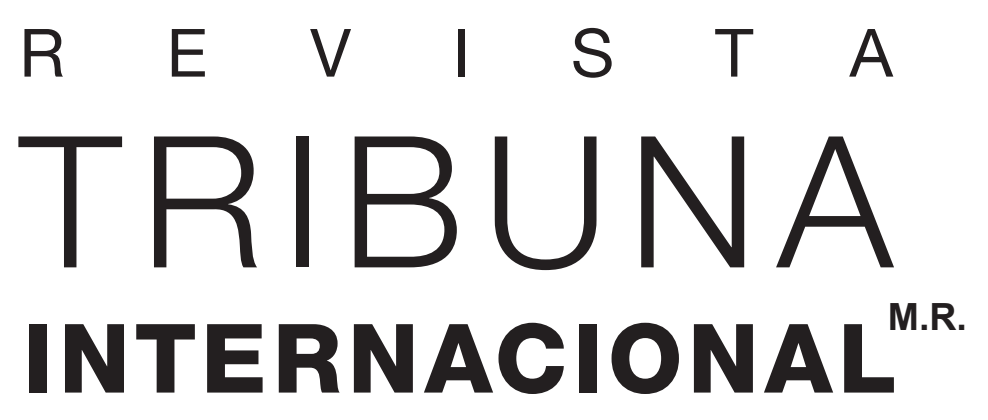

Publicación del Departamento de Derecho Internacional

Volumen $3 / N^{\circ} 5 / 2014$

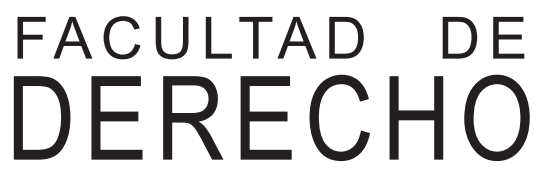




\section{Rector de la Universidad de Chile}

Ennio Vivaldi Véjar

Av. Libertador Bernardo O’Higgins

1058, Santiago

\section{Representante legal}

Roberto Nahum Anuch

Decano de la Facultad de Derecho

de la Universidad de Chile

\section{Director responsable}

Mario Ramírez Necochea

\section{Editora de contenidos}

Rita Lages

\section{Comité editorial}

Ínigo Álvarez Gálvez

(Universidad de Chile, Chile)

Gonzalo Aguilar

(Universidad Andrés Bello, Chile)

José Carlos Fernández Rosas

(Universidad Complutense de Madrid, España)

Claudio Grossman

(American University, EE.UU.)

Mattias Kumm

(New York University, EE.UU.)

Hugo Llanos

(Universidad Central, Chile)

Cecilia Medina

(Universidad Diego Portales, Chile)

Elina Mereminskaya

(Universidad de Chile, Chile)

Mónica Pinto

(Universidad de Buenos Aires, Argentina)

\section{Revista Tribuna Internacional M.R.}

La Revista Tribuna Internacional es una marca registrada y una publicación del Departamento de Derecho Internacional de la Facultad de Derecho de la Universidad de Chile. Su objetivo es fomentar la reflexión, el debate, el análisis y la comunicación sobre el derecho internacional en forma pluralista y con rigor científico. Se publica cada semestre en los meses de junio y diciembre mediante convocatoria abierta a la publicación de artículos y monografías inéditos, comentarios de jurisprudencia, recensiones y comentarios de libros, en los campos de derecho internacional, derechos humanos y relaciones internacionales, tanto en castellano como en inglés.

Volumen 3 / N. 5 / 2014

www.tribunainternacional.uchile.cl ISSN 0719-210X (versión impresa) ISSN 0719-482X (versión en línea)

Departamento de Derecho Internacional Facultad de Derecho Universidad de Chile Av. Santa María 076, $4 .^{\circ}$ piso Providencia, Santiago de Chile

\section{Diseńo y producción:}

Gráfica LOM

www.lom.cl

Impreso en Chile/ Printed in Chile

Se autoriza la reproducción total o parcial del contenido de la publicación, siempre que se reconozca y cite el/ la/ los/ las autor/a/es/as y la publicación, no se realicen modificaciones a la obra y no se la utilice para fines comerciales. 


\section{ÍNDICE}

\section{Artículos}

Aproximaciones históricas acerca de la crisis en Venezuela

Gabriel Álvarez Undurraga

Las dos caras de la política nuclear israelí

Oded Balaban

Nuevas perspectivas de los derechos de los grupos a partir del análisis de la jurisprudencia de la Corte Interamericana de Derechos Humanos sobre los derechos de los pueblos indígenas Jaime Eduardo Gajardo Falcón

Una perspectiva histórica de la política exterior de los Estados

Unidos hacia América Latina en los siglos XIX y XX

Eduardo Ortiz

\section{Comentarios de jurisprudencia}

Reflexiones sobre el derecho internacional y la delimitación marítima. Comentario del fallo de la Corte Internacional de Justicia en el caso Perú c. Chile 


\title{
Nuevas perspectivas de los derechos de los grupos a partir del análisis de la jurisprudencia de la Corte Interamericana de Derechos Humanos sobre los derechos de los pueblos indígenas ${ }^{1}$
}

\author{
New perspectives of group rights on the jurisprudence of the \\ Inter-American Court of Human Rights about indigenous people
}

\section{Jaime Eduardo Gajardo Falcón}

\section{gajardofalcon@gmail.com}

Abogado. Licenciado en Ciencias Jurídicas y Sociales, Universidad de Chile. Magíster en Derecho, Universidad de Chile. Máster en Gobernanza y Derechos Humanos, Universidad Autónoma de Madrid. Máster en Derecho Constitucional, Centro de Estudios Políticos y Constitucionales (España). Doctorando en Derecho, Universidad Autónoma de Madrid. Actualmente se desempeña como personal investigador en formación en la Universidad Autónoma de Madrid y es becario Chile para estudios doctorales en el extranjero.

Resumen: En este trabajo analizaré las nuevas perspectivas de los derechos de los grupos sobre pueblos indígenas a partir de la jurisprudencia de la Corte Interamericana de Derechos Humanos que surgen con la dictación de las sentencias del caso de la Comunidad Indígena Xákmok Kásek v. Paraguay (2010) y del Pueblo Indígena Kichwa de Sarayaku v. Ecuador (2012). Luego de una revisión teórica de los derechos de los grupos, el estudio de las sentencias se centrará en la conceptualización y fundamentación que realizó de ellos la Corte Interamericana de Derechos Humanos. A continuación de la revisión de las sentencias, argumento que la Corte Interamericana de Derechos Humanos cambió su entendimiento de los derechos de los grupos en materia indígena, anclando sus presupuestos en una concepción fuerte de los mismos.

Palabras clave: derechos de grupo, pueblos indígenas, derecho de propiedad comunitaria indígena, Corte Interamericana de Derechos Humanos.

Abstract: The article focuses on the new perspectives of group rights in the jurisprudence of the Inter-American Court of Human Rights after the judgment of the Court's case of the Indigenous Community Xákmok Kásek v. Paraguay (2010) and Kichwa Indigenous People of Sarayaku v. Ecuador (2012). After a theoretical review of the rights of groups, the study of the judgments will focus on a review of the concept and foundation, which was done by the Inter-American Court of Human Rights. Following the review of the case-law, I argue the Inter-American Court of Human Rights changed their understanding of the rights of groups, anchoring budgets thereof, in a strong conception of them.

Keywords: group rights, indigenous peoples, indigenous land rights, Inter-American Court of Human Rights.

\footnotetext{
1 Artículo enviado el 05.03.2014 y aceptado el 25.04.2014.
} 


\section{Introducción}

Los derechos de los grupos, entendidos como aquellos que pertenecen a las colectividades humanas como tal (a los que se ha denominado también como derechos colecti$\operatorname{vos}^{2}$ ), es un concepto controvertido dentro de la teoría del derecho. Se debate sobre su naturaleza. Acerca de si es posible que los grupos sean sujetos de derecho dentro de un Estado democrático con raíces liberales. Se discute sobre la posibilidad que los "grupos" tengan intereses, voluntad, motivaciones morales válidas, etc. Se polemiza sobre la utilidad de tener derechos de grupos y su compatibilidad con los derechos individuales. En fin, el concepto de derechos de grupos es controversial y los académicos liberales y comunitaristas lo han usado como un aspecto central para argumentar sus teorías.

Debido al debate entre liberales y comunitarios a raíz del multiculturalismo, la idea de derechos de los grupos se encuentra muy influenciada (contaminada) con la postura filosófica que se tome al respecto ${ }^{3}$. De esta forma, el reconocimiento de derechos a ciertos grupos culturales implicaría aprobar la crítica comunitarista del liberalismo, y la defensa de los grupos como entes cohesionados; o en su defecto, si uno no considera la utilidad de los derechos de grupo, implicaría entender que el único sujeto moral válido para la asignación de derechos es el individuo, negando la importancia del grupo en la construcción de la identidad y en el ejercicio de la libertad.

Para los teóricos liberales clásicos, los derechos de grupo y los derechos individuales son profundamente incompatibles. Subrayan que una nueva categoría de derechos es innecesaria para adaptar las demandas de las minorías culturales o de otro carácter. En este sentido, los derechos y libertades fundamentales, tal como están, proporcionan un marco lo suficientemente flexible para garantizar la coexistencia pacífica de los diferentes grupos en las sociedades democráticas. Así, la doctrina liberal de la tolerancia junto con el principio de neutralidad del Estado, ofrece un marco adecuado para abordar la diversidad y dar cabida a las minorías ${ }^{4}$.

2 Para Bhikhu Parekh, el concepto "derechos colectivos" es genérico y los "derechos de los grupos" son especies que pertenecen a ese género. Asimismo, realiza una distinción entre derechos colectivos derivados y primarios, basada en la forma o naturaleza de su adquisición. Cuando los individuos ponen en común sus derechos o los ceden a la colectividad, se habla de derechos colectivos derivados. Si los grupos adquieren derechos por lo que son y no de forma derivada, estaríamos en presencia de un derecho colectivo primario y que serían los que interesarían para el presente trabajo. Véase, PAReKh, B. Repensando el multiculturalismo. Istmo, Madrid, 2005, p. 317.

3 Véase, Escudero, R. "Tensiones conceptuales en el liberalismo y en el multiculturalismo". En: Giraudo, L. (Ed.). Derechos, costumbres y jurisdicciones indigenas en la América Latina contemporánea. Centro de Estudios Políticos y Constitucionales, Madrid, 2008, pp. 37-53.

4 Torbisco, N. Group Rights as Human Rights. A Liberal Approach to Multiculturalism. Springer, Barcelona, 2006, pp. 5-8. 
En el contexto americano, los derechos de los grupos se han utilizado para conceptualizar la propiedad indígena sobre los territorios que los pueblos indígenas ocupan o han ocupado ancestralmente. En ese sentido, los derechos de los grupos han jugado un papel fundamental en la defensa de los derechos humanos de los pueblos indígenas, gozando de un amplio desarrollo normativo (nacional e internacional) e incipiente jurisprudencia (nacional e internacional), poniendo en tela de juicio la opinión mayoritaria de la teoría liberal al respecto5.

Por su parte, la Comisión Interamericana de Derechos Humanos (en adelante «CIDH») ha defendido ante la Corte Interamericana de Derechos Humanos (en adelante «Corte IDH») una concepción de derechos de grupo, en lo que se refiere a la propiedad indígena, en la cual tanto la titularidad como el ejercicio corresponden al grupo en todo o en parte. Sin embargo, con una visión más restrictiva, la Corte IDH ha señalado que la propiedad indígena es un derecho colectivo, cuyos titulares son las personas individuales que conforman los pueblos indígenas o tribales, y su ejercicio se desenvuelve en sistemas de propiedad colectiva ${ }^{6}$.

La tesis central del presente trabajo es que los casos propuestos marcan un punto de inflexión en la jurisprudencia de la Corte IDH sobre los derechos de los grupos en materia indígena ${ }^{7}$. Sostenemos que en el caso de la comunidad indígena Xákmok Kásek, aunque la Corte IDH no cambia radicalmente su jurisprudencia, con algunos aspectos de la sentencia y el voto concurrente del Juez Eduardo Vio Grossi, se sientan las bases para una conceptualización de los derechos de grupo que confluye con la que venía realizando la $\mathrm{CIDH}$ y que entiende que la propiedad comunal indígena es un derecho de grupo tanto en su titularidad como en su ejercicio, transformando a la propiedad comunal indígena en un derecho de grupo propiamente tal ${ }^{8}$. Ello, posteriormente, se

5 Sobre la abundante literatura al respecto, destacamos la siguiente: Clavero, B. Derecho indígena y cultura constitucional en América. Siglo veintiuno editores, Madrid, 1994, 210 pp.; МaскаY, F. Los derechos de los pueblos indígenas en el sistema internacional. Asociación Pro Derechos Humanos, Lima, 1999, 457 pp.; ANAYA, J. Los pueblos indígenas en el derecho internacional. Trotta, Madrid, 2005, 493 pp.; Aguilar, G. Dinámica Internacional de la cuestión indígena. Santiago. Librotecnia, 2007, 658 pp.

6 Para un estudio amplio de los derechos de los grupos en el Sistema Interamericano de Protección de los Derechos Humanos y, por ende, el entendimiento que tienen ambos órganos del sistema, véase, Gajardo Falcón, J. "Derechos de los grupos en el Sistema Interamericano de Protección de los Derechos Humanos". En: Hierro, L. (Coord.). Autonomia individual frente a autonomía colectiva. Derechos en conflicto. Marcial Pons, Madrid, 2014, pp. 145-171.

7 La comparación la realizamos con los fallos de la Corte IDH en los casos de la Comunidad Mayagna (Sumo) Awas Tingni v. Nicaragua (2000); Comunidad Indígena Yakye Axa v. Paraguay (2005); Comunidad Indígena Sawhoyamaxa v. Paraguay (2006).

8 Las consecuencias jurídicas de la confluencia de posturas entre la Corte IDH y la CIDH son las posibles tensiones, internas y externas, entre los derechos del grupo y los derechos individuales. La relación entre el derecho colectivo de propiedad y el derecho individual, analizado desde un punto de vista externo, estaría dado en su relación con propietarios individuales (no comunitarios) que reclamen el dominio del mismo territorio 
ve ratificado en el entendimiento que hizo la Corte IDH en el caso del pueblo indígena Kichwa de Sarayaku v. Ecuador (2012).

Así, en el presente trabajo desarrollaré los siguientes temas: revisaré los aspectos teóricos más relevantes de los derechos de los grupos (2); junto con entregar los antecedentes generales de los casos, aplicaré el marco conceptual en el análisis de las nuevas perspectivas que se abren en la jurisprudencia de la Corte IDH (3); y finalmente, expondré mis conclusiones al respecto y las perspectivas de desarrollo del tema (4).

\section{Aspectos teóricos relevantes para el análisis de los derechos de los grupos en materia indígena}

A continuación revisaré las propuestas que hacen Luis Rodríguez Abascal y Neus Torbisco sobre los derechos de los grupos. Estos autores buscan, desde la teoría del derecho, presentar una visión de los derechos de los grupos que se acomode a los presupuestos liberales de la teoría general de los derechos humanos9. Luego, revisaré, brevemente, la recepción que han tenido los derechos de los grupos en el marco jurídico internacional, particularmente en el Convenio $\mathrm{N}^{\circ} 169$ sobre Pueblos Indígenas y Tribales en Países Independientes, de la Organización Internacional del Trabajo de1989 (en adelante «Convenio N 169 de la OIT») y la Declaración de Naciones Unidas sobre los derechos de los pueblos indígenas, adoptada en septiembre de 2007 (en adelante «DPPI»).

Ambos planteamientos teóricos y el marco jurídico internacional, serán utilizados de forma comparada al momento de analizar la forma en que la Corte IDH se pronuncia acerca de los derechos de grupo.

o en su defecto, en cuanto a las obligaciones estatales. En este plano, teóricamente, no deberían existir mayores inconvenientes, ya que se trata de conflictos entre sujetos propietarios (colectivos e individuales) a los que se aplicarían reglas para determinar el dominio y salvaguardar los derechos de terceros adquirentes de buena fe. Donde, eventualmente, podría existir el peligro a la anulación total de un derecho humano individual, es en las relaciones internas de la propiedad comunitaria indígena, donde la protección del derecho de propiedad comunal como derecho de grupo podría impedir el derecho de salida de un miembro de la comunidad o el ejercicio de su derecho de propiedad desde un punto de vista individual. Al respecto, véase, Gajardo FaLcón, op. cit., pp. 166-169.

9 Las razones que justifican la elección de estos autores para el marco teórico del trabajo son dos: (1) ambos autores revisan la pertinencia de los derechos de los grupos dentro de la tradición occidental del derecho y (2) la relevancia e impacto que tienen ambos tanto en la tradición continental como anglosajona del derecho. 


\subsection{Los tres planos de análisis de Luis Rodríguez Abascal}

Distinguiendo niveles de análisis, Luis Rodríguez Abascal argumenta a favor de los derechos de los grupos, luego de analizar las críticas que han tenido desde la filosofía política liberal en tres planos: conceptual, normativo y práctico. Diferenciar los planos desde los cuales se habla del tema y entenderlos como filtros consecutivos permite que algunas reclamaciones puedan ser entendidas como derechos de grupo. "En cada uno de esos terrenos el debate tiene un objeto diferente. En el terreno conceptual se discute si, dado el concepto de "grupo» y el concepto de «derecho» que manejamos, se puede hablar de los grupos como titulares de derechos y, en todo caso, qué concepto de "grupo" y de «derecho» serían preciso para que pudiéramos hablar de derechos de grupo. En el terreno normativo se discute cuál es la importancia moral de ciertos grupos humanos y si esa importancia o alguna de las circunstancias en que se encuentran esos grupos justifican la asignación de derechos al grupo. En el terreno pragmático se discute cuáles son los requisitos que deben cumplir ciertos grupos para que los derechos que se predican de ellos puedan ser llevados a la práctica” ${ }^{10}$.

En este sentido, el primer obstáculo que deben sortear los derechos de los grupos, es si estos pueden considerarse derechos en un sentido subjetivo. Utilizando un concepto de derecho subjetivo funcional sería posible que los grupos tengan derechos como tal ${ }^{11}$.

Luego, ¿tienen los grupos razones para tener derechos? Esta pregunta, en el plano conceptual, admitiría una respuesta positiva, tanto desde la teoría del interés defendida Ihering, Bentham, y Raz, como desde la teoría de la voluntad planteada por Hart ${ }^{12}$.

Así, los derechos de los grupos no tendrían objeciones analíticas ${ }^{13}$ para que se puedan considerar derechos desde un punto subjetivo. Sin embargo, para que consideremos derechos de grupo propiamente tal, se deberán entender aquellos derechos que no puedan ser descompuestos en derechos individuales, ya que de lo contrario, no serían derechos de grupo, sino que individuales asignados a grupos de personas ${ }^{14}$. Los derechos de au-

${ }^{10}$ Rodríguez-Abascal, L. "El debate sobre los derechos de grupo". En: Díaz, E. y Colomer, J. L. (Eds.). Estado, Justicia y Derechos. Alianza Editorial, Madrid, 2002, p. 414.

${ }^{11}$ Ídem., p. 415.

${ }^{12}$ Véase, Rodríguez-Abascal, L. "On the admissibility of group rights". Annual Survay of International \& Comparative Law, Vol. 9, n. ${ }^{\circ}$ 1, 2003, pp. 101-110.

${ }^{13}$ Según Nancy Fraser, se debe intentar no constitucionalizar o institucionalizar los derechos de los grupos, porque al ser distinciones de "estatus" pueden resultar muy difíciles de modificar. Véase, Fraser, N. "La justicia social en la era de la política de la identidad: Redistribución, reconocimiento y participación". En: Fraser, N. y Honneth, A. ¿Redistribución o reconocimiento?. Morata, Madrid, 2006, p. 79.

${ }^{14}$ Luis Rodríguez-Abascal señala que en este punto coinciden tanto los partidarios de los derechos de los grupos, como sus detractores. Véase, Rodríguez-Abascal, "On the admissibility...”, op. cit., p. 416. 
togobierno y de representación, podrían considerarse verdaderos derechos de grupo y que cumplen con todos los requisitos conceptuales para ello. Asimismo, sostengo que también se podría considerar un derecho de grupo, desde un punto de vista conceptual, el entendimiento que ha realizado la $\mathrm{CIDH}$ sobre la propiedad comunal indígena ${ }^{15}$.

En el plano normativo, se han realizado al menos cinco objeciones, para las pretensiones que aspiran convertirse en derechos de grupo. Sin embargo, dichos obstáculos son salvables no sólo para los derechos de los grupos, sino también para otras situaciones jurídicas. En primer lugar, se objeta que las pretensiones que aspiran en convertirse en derechos de grupo, no cumplen con el supuesto de que el grupo lo podamos considerar un agente moral. Esta crítica está realizada desde un concepto de individualismo ético, donde el individuo es el único al que podríamos conceder valor moral. Esta objeción es posible salvarla de dos formas. La primera, por el hecho de que "para concebir que algunos grupos podrían ser titulares de derechos sólo sería necesario admitir algún modo válido de forma la voluntad colectiva" ${ }^{16}$. La segunda, en el sentido de que para ser sujeto de derechos morales, no es necesario ser agente moral. "Si para ser titular de derechos exigiésemos ser un agente moral, responsable de sus actos, entonces no sólo los derechos de los grupos quedarían descartados, sino también los derechos de los niños, los derechos de los disminuidos psíquicos, o los derechos de los animales (...)" ${ }^{\prime 17}$. Concebir derechos de grupo, puede implicar rechazar que sólo el individuo es agente moral, por ende criticar el individualismo ético. Sin embargo, se puede aceptar el individualismo ético, y afirmar los derechos de los grupos, ya que sólo basta para ello, señalar que para tener derechos legales no es preciso ser agente moral ${ }^{18}$.

Como segunda objeción, se ha planteado que los derechos de los grupos no son necesarios normativamente hablando, porque ellos no tienen un valor diferente al de sus miembros. Esta crítica se supera desde que se entiende que el grupo tiene un valor moral fundamental en la formación de la identidad del individuo (Taylor ${ }^{19} \mathrm{y} \mathrm{Raz}^{20}$ ), con lo que tendría un valor en sí mismo. En el mismo sentido, el grupo es el lugar donde el individuo ejerce su autonomía $^{21}$. Finalmente, y como tercer contra argumento, no todos los bienes o intereses son posibles de reducir a la suma de bienes o intereses individuales ${ }^{22}$.

\footnotetext{
$15 \mathrm{Al}$ respecto, véase, Gajardo Falcón, op. cit., pp. 156-160.

16 Rodríguez-Abascal, "On the admissibility...", op. cit., p. 418.

17 Ibidem.

${ }^{18}$ Idem, pp. 418-419.

${ }^{19}$ Los dos trabajos de Charles Taylor más relevantes, al respecto, son, TAYLOR, Ch. Fuentes del yo: la construcción de la identidad moderna. Paidós, Barcelona, 1996, 800 pp.; El multiculturalismo y "la política del reconocimiento", $2^{\mathrm{a}}$ ed. Fondo de cultura económica, México, 2009, 246 pp.

${ }^{20}$ Véase, Raz, J. The morality of freedom. Clarendon Press, Oxford, 1988, 435 pp.

${ }^{21}$ Sobre argumentos para fundamentar el valor de los grupos culturales dentro de la sociedad, véase, GUTMANN, A. La identidad en democracia. Katz Editores Buenos Aires, 2008, pp. 66-69.

${ }^{22}$ Para Kymlicka el debate no tiene sentido en el plano de las "protecciones externas" y que serían el fundamento
} 
Una tercera crítica a los derechos de los grupos, dice relación con la idea de que otorgar dichos derechos puede implicar la opresión a los miembros de los grupos. Por lo que sería más aconsejable garantizar derechos individuales a miembros de grupos oprimidos que al grupo. Esta crítica general es poco clara al ser analizada según el tipo de derecho de grupo que se trate. Por ejemplo, si hablamos de derechos especiales de representación, no se vislumbra como ello podría implicar la opresión de los individuos de ese grupo. En este punto, resulta útil lo planteado por Kymlicka, en cuanto a que los derechos de los grupos se debieran conceptualizar como una protección externa del grupo, es decir, una protección del grupo desaventajado frente a la cultura o grupo dominante. Ello teniendo presente que las "restricciones internas" (aquellas que limitan derechos humanos por parte del grupo a sus individuos) no se toleran como parte de los derechos legítimos del grupo ${ }^{23}$.

En cuarto lugar, se ha señalado que los derechos de los grupos generan problemas muy graves de cooperación social. Al establecer derechos de grupos, los individuos tenderían a asociarse para formar parte de grupos, lo que produciría tensión y fragmentación social. Lo anterior, implicaría entender que la sociedad no se encuentra fragmentada y que otorgar derechos de grupo produciría la misma. Sin embargo, quienes argumentan en favor de los derechos de grupo, señalan que la sociedad ya se encuentra fragmentada y que dichos derechos sólo buscan equilibrar las relaciones sociales e intergrupales dentro de sociedades multiculturales.

En quinto lugar, los detractores de los derechos de los grupos, señalan que su consagración es inoficiosa, debido a que los supuestos beneficios que ellos traerían no se encuentran garantizados. Esta crítica, especulativa y general, queda superada desde el momento en que se acepta que reconocer derechos de grupo tiene un valor intrínseco.

Como se puede apreciar, sería posible reconocer derechos a los grupos, tanto desde un punto de vista conceptual como normativo, lo que nos lleva a revisar sus posibles problemas prácticos. En este plano, para poder construir derechos de los grupos, se deben superar una serie de dificultades.

Primero, hay problemas para determinar los límites del grupo, es decir, establecer sus miembros con precisión. En algunos casos el grupo cultural alberga en su interior otros grupos $^{24}$, con ello, la definición del grupo puede traer inconvenientes de infra o supra

principal de su idea de derechos diferenciados de los grupos. El debate tiene implicancias en cuanto a las "restricciones internas". Sin embargo, con el criterio que utiliza de que ellas sólo son admisibles cuando no limitan arbitrariamente o afectan la esencia de los derechos fundamentales de sus miembros, el debate también se vuelve estéril. Véase: Kyмlicka, W. Ciudadanía multicultural. Paidós, Barcelona, 1995, p. 75.

${ }^{23}$ Idem, pp. 57-76.

${ }^{24}$ Véanse los ejemplos que entrega se en: Rodríguez-Abascal, “On the admissibility...", op. cit., p. 427. 
inclusión. A diferencia de lo expresado por Rodríguez Abascal, esta complejidad no la veo como tal, desde el momento en que se especifica el rango de acción del multiculturalismo a los grupos etnoculturales, minorías nacionales e inmigrantes, dicho problema se resuelve. De todas formas, como veremos en el punto siguiente, un análisis que se centra en las justificaciones y principios no se debería detener ante desacuerdos en este plano.

Segundo, señala la dificultad que presenta el dinamismo de los grupos, es decir, que estos se transforman e incluso desaparecen. Creo que ello es correcto para los grupos de interés, pero no para los culturales (minorías nacionales, indígenas e inmigrantes), debido a que ellos presentan una estabilidad bastante importante. Por ejemplo, en el caso de los pueblos indígenas, la estabilidad es mayor y anterior a la del propio Estado nacional.

\subsection{La propuesta integradora de Neus Torbisco}

Rompiendo con la forma de enfocar el tema y centrándose en las demandas de las minorías culturales, sostiene que los derechos de grupo no son intrínsecamente contrarios a los derechos individuales sino que los complementan, con el fin de honrar algunos valores fundamentales que caracterizan las teorías liberales ${ }^{25}$.

Neus Torbisco explora su tesis central fuera de los límites que ha puesto el debate entre liberales y comunitaristas sobre los derechos de grupo. Critica la correlación entre los derechos individuales y el liberalismo; y el comunitarismo y los derechos de grupo, por ser engańoso. Esta analogía no sólo se basaría en dudosas premisas teóricas, también desvía la atención de las cuestiones normativas pertinentes. El hecho de que las minorías y grupos culturales expresen sus demandas en términos de derechos de grupo propicia un análisis que se centra fundamentalmente en los problemas formales implícitos en esta categoría de derechos, dejando las cuestiones normativas importantes sin explorar.

Para Neus Torbisco, siguiendo el análisis de Kymlicka, la mayoría de los debates sobre derechos de las minorías no son cuestiones entre una mayoría liberal y minorías comunitarias, sino entre liberales sobre el significado del liberalismo ${ }^{26}$. Es decir, se trata de debates entre los diferentes grupos y personas que están en desacuerdo sobre la interpretación de los principios liberales democráticos en las sociedades multiétnicas y multiculturales ${ }^{27}$.

\footnotetext{
25 Torbisco, op. cit., pp. 243-247.

26 Sobre la falacia de generalización en la que caen autores liberales al analizar algunas de las demandas de grupos culturales, véase, Idem, pp. 65-77.

27 Idem, pp. 36-37.
} 
Para fundamentar sus conclusiones, Neus Torbisco comienza analizando el concepto jurídico de minoría, ya que en dicho espacio se centró desde 1970 el debate sobre los derechos de grupo, y propone que dicho concepto sea entendido como uno de tipo controvertido, siguiendo lo que entiende Jeremy Waldron al respecto ${ }^{28}$. Con ello, carecería de sentido tratar por separado la cuestión de definir a una minoría del problema de la atribución de derechos específicos para la misma. La existencia de desacuerdos sobre el significado del término no constituye una razón suficiente para eludir el tema de los derechos de grupo ${ }^{29}$. Lo anterior, nos permite apreciar un contraste importante con el trabajo de Rodríguez Abascal, ya que es en dicho plano donde él visualiza las mayores dificultades para los derechos de los grupos, en razón a qué entendemos, cómo limitamos, cómo conformamos y proyectamos los grupos o minorías. Sin embargo, para Neus Torbisco lo central no es el aspecto práctico, sino los principios que se encuentran en juego ${ }^{30}$. Lo importante, radica en enfocarse en la legitimidad moral y política de los derechos de los grupos y las demandas de las minorías culturales desde el liberalismo ${ }^{31}$. Así, luego de analizar principalmente los trabajos de Taylor, Raz y Kymlicka, concluye que la pertenencia individual a un grupo cultural constituye un interés legítimo fundamental para el bienestar individual, a los que los catálogos de derechos individuales civiles y políticos no pueden proteger adecuadamente, ni de forma directa ni indirecta ${ }^{32}$.

Neus Torbisco, basándose en las críticas formuladas por Taylor y Kymlicka al enfoque tradicional del liberalismo sobre la diversidad cultural, argumenta que el substrato del que debería nutrirse una teoría de los derechos colectivos de las minorías culturales, que va más allá del modelo de tolerancia y no discriminación propio de los derechos individuales, son los principios de libertad, igualdad y dignidad que postula la vertiente cultural del liberalismo ${ }^{33}$. De los autores precitados obtiene la idea de una intrínseca conexión entre la libertad y la autonomía, y la necesidad de reconocimiento de la identidad, fruto o influida por el grupo o contexto social ${ }^{34}$.

Luego, para fundamentar sus planteamientos de los derechos colectivos, Neus Torbisco utiliza una combinación de las propuestas de Kymlicka y de la política del reconocimiento de Taylor. Por un lado, la idea de cultura social, que Kymlicka toma como punto de partida para su modelo de justicia en las sociedades multiculturales, le proporciona una base

\footnotetext{
28 Véase, Waldrom, J. "Vagueness in Law and Language: Some Philosophical Issues”. California Law Review, vol. 82, n. ${ }^{\circ}$ 3, 1994 , pp. 509-540.

29 Torbisco, op. cit., pp. 19-42.

30 Idem, p. 28.

${ }^{31}$ En un sentido similar, Parekh argumenta que lo importante es centrarse en las demandas de los grupos, y preguntarse qué colectividades deberían tener derechos y bajo qué condiciones. Véase, PAREKH, op. cit., p. 322.

32 Torbisco, op. cit., pp. 141-157.

33 Idem, pp. 189-190.

${ }^{34}$ Idem, p. 190.
} 
sólida para su teoría. Le permite argumentar que la pertenencia cultural es un bien básico, sin caer en un discurso esencialista de la identidad que lleva a la defensa de un derecho a la supervivencia cultural de las diferentes culturas. Por la misma razón, señala que los derechos de grupo no deberían servir para reproducir artificialmente elementos culturales que ya se han perdido, o para limitar la libertad de los miembros de las minorías culturales que optan por asimilarse a la cultura dominante. Por otro lado, teniendo en cuenta las observaciones críticas formuladas por la "política del reconocimiento" de Taylor, le permite complementar la teoría de Kymlicka con el fin de contrarrestar con éxito los desafíos de la misma. La correlación entre el reconocimiento de la identidad, la autoestima y la dignidad humana justifican la importancia del derecho a la propia cultura, incluso cuando la asimilación a la cultura dominante no plantea excesivos problemas ${ }^{35}$.

Por tanto, para Neus Torbisco los derechos de los grupos como derechos fundamentales se justifican por la relevancia moral intrínseca de la pertenencia cultural. En dicho sentido apunta que las culturas minoritarias en los Estados multinacionales o multiétnicos tienen un reclamo justificable y, por ende, las normas constitucionales deben reconocer explícitamente derechos de grupo ${ }^{36}$.

Finalmente, es importante señalar que para Neus Torbisco la fundamentación de los derechos de grupo es de tipo sustancial, diferenciándose de las que denomina instrumental, que sólo enfatizan en la relevancia de la pertenencia cultural para garantizar la realización de otros valores ${ }^{37}$.

\subsection{Marco jurídico internacional de los derechos de los grupos en materia indígena}

Durante las últimas tres décadas, tanto en el derecho internacional, como en el plano constitucional, se ha producido un vertiginoso desarrollo de los derechos de los pueblos indígenas. En el ámbito internacional se fue produciendo un cambio de enfoque, decidiéndose que para acomodar la diversidad cultural no bastaba con la protección de los derechos humanos por la vía individual ${ }^{38}$. El punto de inflexión se produce con la aprobación del Convenio $\mathrm{N}^{\circ} 169$ de la OIT. Éste es el primer instrumento internacional que se refiere a los "Pueblos Indígenas" como tal.

35 Idem, p. 190.

36 Idem, p. 191.

37 Idem, pp. 190-191.

38 Véase, Torbisco, N. "Derechos indígenas: reconocimiento y desafíos para la democracia constitucional y para los derechos humanos”. En: Hierro, L. (Coord.). Autonomia individual frente a autonomía colectiva. Derechos en conflicto. Marcial Pons, Madrid, 2014, pp. 82-127. 
El Convenio $\mathrm{N}^{\circ} 169$ de la OIT "separó radical y definitivamente el tema indígena de la cuestión de las minorías, en la medida que los indígenas aparecen con derechos colectivos reconocidos en forma explícita, cuestión que no ocurre de la misma manera con las minorías" ${ }^{39}$. Esto es, a nuestro juicio, lo más importante del Convenio.

Avanzando en la protección de los derechos de los pueblos indígenas la DPPI reforzó las dimensiones colectivas de los derechos humanos de los pueblos indígenas. La declaración, en sus artículos 3 y 4 , reconoce expresamente el derecho a la libre determinación, asociado al autogobierno y la autonomía, para resolver sus asuntos internos, disponer de medios para ello y elegir libremente su desarrollo económico, social y cultural.

En el mismo sentido, en el artículo 5 de la DPPI, se reconoce el derecho de los pueblos indígenas a "conservar y reforzar sus propias instituciones políticas, jurídicas, económicas, sociales y culturales, manteniendo a la vez su derecho a participar plenamente, si lo desean, en la vida política, económica, social y cultural del Estado". Como se puede apreciar, hay un reconocimiento explícito al autogobierno y, por ende, a la dimensión colectiva de sus derechos. En los artículos 11, 12, 13, 14, 15, 16 y 17, se establece el derecho de los pueblos indígenas a lo que se ha denominado como "supervivencia cultural", con el deber por parte del Estado de adoptar medidas eficaces para asegurar su protección. El artículo 13 en su punto primero señala el derecho a la práctica de la cultura y en el punto segundo, el deber del estado a asegurar dicho derecho, es decir el derecho a la "supervivencia cultural".

En similares términos al del Convenio $\mathrm{N}^{\circ} 169$ de la OIT, la DPPI reconoce derechos de autogobierno, de representación, de poliétnicidad (especialmente de educación) y en general, se vela por un trato intercultural y de reconocimiento con el Estado que alberga en su seno pueblos indígenas ${ }^{40}$.

Como se ha podido apreciar, el derecho internacional para los pueblos indígenas se ha desarrollado ampliamente, tomando decisiones concretas por reconocer estatus a ellos, y estableciendo, entre otros aspectos, de forma expresa derechos de grupo a los pueblos indígenas. Por su parte, los Estados que conforman América Latina no se han encontrado exentos del desarrollo internacional de los derechos de los pueblos indíge-

\footnotetext{
39 BengoA, J. La emergencia indígena en América Latina. Fondo de Cultura Económica, Santiago, 2007, p. 273.

40 De forma similar, pero en razón de la realidad de americana, en el año 1989 la Asamblea General de la OEA solicitó a la CIDH la preparación de un instrumento jurídico relativo a los derechos de las "poblaciones indígenas". Luego de un largo proceso de trabajo con organizaciones de la sociedad civil y grupos indígenas, la CIDH en 1997 aprobó el Proyecto de Declaración Americana sobre los Derechos de los Pueblos Indígenas. En marzo de 1997 la CIDH puso el proyecto de declaración a disposición de la Asamblea General de la OEA, el que no ha sido aprobado hasta la fecha. El proyecto de declaración es un instrumento internacional muy avanzado y que en gran parte de sus disposiciones ha sido recogido en la DPPI.
} 
nas. En su mayoría, han aprobado los Convenios señalados, suscrito las declaraciones mencionadas y han constitucionalizado los derechos de los pueblos indígenas ${ }^{41}$.

Los aspectos teóricos revisados y el marco jurídico internacional, son tomados en consideración por la Corte IDH al momento de realizar la interpretación de Convención Americana de Derechos Humanos (en adelante "CADH») en los casos sometidos a su consideración. De hecho, como podremos apreciar en el próximo apartado, la evolución del derecho internacional al respecto será una de las bases de apoyo para las nuevas perspectivas de los derechos de los grupos que hemos identificado.

\section{Análisis de dos fallos recientes de la Corte IDH sobre los derechos de los grupos en materia indígena}

\subsection{Aspectos generales del caso de la Comunidad Indígena Xákmok Kásek v. Paraguay}

El caso se relaciona con los derechos de una comunidad indígena que habita en Paraguay, específicamente en la región del Chaco. En dicha localidad hay presencia de hasta 17 etnias indígenas diferentes con representación de las cinco familias lingüísticas en las que se han clasificado a los pueblos indígenas existentes en el Paraguay. La Comunidad, conformada actualmente por 66 familias, se originó a partir de miembros de aldeas Sanapaná y Enxet (de la familia lingüística Enlhet-Enenlhet) que recorrían tradicionalmente el área del Chaco, el que reclamaban parte del territorio como tradicional, y se asentaron en la primera mitad del siglo XX en el lugar conocido como Xákmok Kásek, que le dio su nombre a la Comunidad.

El caso se inició el 3 de julio de 2009 cuando la CIDH presentó una demanda contra la República del Paraguay ante la Corte IDH solicitando que estableciera la responsabilidad internacional del Estado por la supuesta falta de garantía del derecho de propiedad ancestral de la Comunidad y sus miembros, debido a que desde 1990 se encontraría en tramitación la solicitud de reivindicación territorial de la Comunidad indígena, sin que hasta la fecha de interposición de la demanda se hubiera resuelto satisfactoriamente. Así, la CIDH solicitó a la Corte IDH que declarara la responsabilidad del Estado por violación de los derechos consagrados en los artículos 3 (Derecho al Reconocimiento de la Personalidad

${ }^{41}$ Véase, Gargarella, R. "Nuevo constitucionalismo latinoamericano y derechos indígenas". En: Hierro, L. (Coord.). Autonomía individual frente a autonomía colectiva. Derechos en conflicto. Marcial Pons, Madrid, 2014, pp. 129-143. 
Jurídica), 4 (Derecho a la Vida), 8.1 (Garantías Judiciales), 19 (Derecho del Niño), 21 (Derecho a la Propiedad Privada) y 25 (Protección Judicial) de la CADH, en relación con las obligaciones establecidas en los artículos 1.1 (Obligación de Respetar los Derechos) y 2 (Deber de Adoptar Disposiciones de Derecho Interno) de la misma ${ }^{42}$.

El Estado de Paraguay al contestar la demanda, indicó que no había violado el derecho a la propiedad comunitaria de la Comunidad consagrado en la legislación interna, pero reconoció que por circunstancias de hecho que no le eran imputables, no pudo satisfacer el derecho debidamente. Además, el Estado le solicitó a la Corte IDH que desestimara las pretensiones formuladas por la CIDH y ofreció una "solución amistosa" que reiteró durante la audiencia pública. Finalmente, el Estado señaló que se allanaba al pedido de reparación ${ }^{43}$.

Además, el Estado solicitó la suspensión del proceso debido a las contradicciones encontradas en la denominación y pertenencia étnica de la Comunidad. Argumentó que dichas diferencias le impedirían la titulación de tierras a su favor y no se adecuaría a las prescripciones del Estatuto Indígena y a la normativa internacional. Señaló que los distintos escritos presentados por los representantes de la Comunidad producen confusiones en cuanto a la identificación o pertenencia étnica de la misma, ya que en algunos casos aparece como perteneciente al pueblo Enxet, en otros como Enxet-Lengua y en otras oportunidades como Sanapaná. Para el Estado, la pertenencia étnica o a un pueblo constituía un elemento esencial para la transferencia de la propiedad. Finalmente, indicó que debido a confusiones en cuanto al nombre de la Comunidad sus líderes se encontrarían registrados como líderes de la "Comunidad Zalazar", lo cual haría imposible la titulación de las tierras a favor de la misma hasta que se regularizara dicha documentación ${ }^{44}$.

Debido a lo anterior, la Corte IDH, antes de entrar en el fondo de la cuestión, analiza ambas peticiones del Estado, rechazándolas en conformidad a los argumentos que paso a señalar. Primero, sobre la solicitud de solución amistosa y el allanamiento, la Corte IDH considerando la inconformidad de la CIDH y las víctimas con la solución propuesta por el Estado y además que el Estado en el "allanamiento" niega los hechos y la violación a los derechos de la $\mathrm{CADH}$, no reconociendo su responsabilidad internacional, decide analizar el fondo de la controversia internacional ${ }^{45}$.

\footnotetext{
${ }^{42}$ Según la CIDH, "[l]o anterior ha significado no sólo la imposibilidad de la Comunidad de acceder a la propiedad y posesión de su territorio, sino que, por las propias características de la misma, ha implicado mantenerla en un estado de vulnerabilidad alimenticia, médica y sanitaria, que amenazan en forma continua la supervivencia de los miembros de la Comunidad y la integridad de la misma”. CorTe IDH, Comunidad Indígena Xákmok Kásek v. Paraguay, 24 de agosto 2010, Serie C N² 214, párrs. 1-3.

43 Idem, párr. 27.

${ }^{44}$ Idem, párr. 33.

${ }^{45}$ Idem, párrs. 27-32.
} 
En segundo lugar, la Corte IDH rechaza la solicitud de suspensión del proceso realizada por el Estado, argumentando que "la composición multiétnica de la Comunidad es un hecho acreditado y el Estado lo conocía o debió conocer previamente. Las distintas referencias como pertenecientes al pueblo Enxet o como descendientes del pueblo Sanapaná obedecen a razones históricas o circunstanciales, por lo que el argumento del Estado no constituye razón suficiente para la suspensión del presente caso" ${ }^{36}$.

Luego, la Corte IDH pasa a revisar el fondo de la causa, utilizando el siguiente esquema: (1) derecho a la propiedad comunitaria, garantías judiciales y protección judicial. Desarrollando por separado los hechos ${ }^{47}$, el derecho a la propiedad comunitaria ${ }^{48} y$ las afectaciones a la identidad cultural de los miembros de la Comunidad como consecuencia de la no restitución de su territorio tradicional ${ }^{49}$; (2) el derecho a la vida, analizando el derecho a la vida digna $a^{50}$ y los fallecimientos ocurridos en la Comunidad ${ }^{51}$; (3) el derecho a la integridad personal $^{52}$; (4) el derecho al reconocimiento de la personalidad jurídica ${ }^{53}$; (5) los derechos de los niños y niñas ${ }^{54}$, y (6) el deber de respetar y garantizar los derechos sin discriminación ${ }^{55}$.

En cuanto a las decisiones de fondo, la sentencia de la Corte IDH, en lo relativo a la propiedad comunitaria indígena sobre sus territorios ancestrales, concluyó que el territorio reclamado por la Comunidad son sus tierras ancestrales y las más aptas para el asentamiento de las mismas. Además, estableció que el procedimiento administrativo iniciado por los líderes de la Comunidad en 1990 para la recuperación de su territorio ancestral no se llevó a cabo por parte del Estado con la diligencia debida, ni tramitado en plazo razonable, no constituyendo una posibilidad real para que los miembros de la Comunidad recuperaran su territorio. Para la Corte IDH, el Estado ignoró y descono-

${ }^{46}$ Idem, párr. 43.

${ }^{47}$ En los hechos de la causa, la Corte IDH revisa (1) la situación de las comunidades indígenas en Paraguay; (2) el reclamo territorial de la Comunidad Xákmok Kásek y sus miembros y (3) la declaración de reserva natural privada sobre parte del territorio reclamado. Idem, párrs. 56-85.

48 En el derecho a la propiedad comunitaria, la Corte IDH revisa (1) cuestiones relativas a las tierras reclamadas (carácter tradicional; posesión y exigencia para el reconocimiento de la propiedad comunitaria; vigencia del derecho a reclamar las tierras tradicionales; y alegada satisfacción del derecho de los miembros de la Comunidad a su territorio tradicional con tierras alternativas); (2) acciones del Estado llevadas a cabo para recuperar las tierras tradicionales (debida diligencia en el trámite administrativo; principio de plazo razonable en el procedimiento administrativo; efectividad del recurso administrativo de reivindicación de tierras indígenas; (3) sobre el decreto que declara parte del área reclamada como área silvestre protegida y (4) la supuesta falta de diligencia de recursos en la vía judicial. Idem, párrs. 86-170.

${ }^{49}$ Idem, párrs. 171-182.

${ }^{50}$ En el derecho a la vida digna, la Corte IDH revisa (1) el acceso y calidad del agua; (2) la alimentación; (3) la salud y (4) la educación. Idem, párrs. 194-217.

${ }^{51}$ Idem, párrs. 218-234.

52 Idem, párrs. 235-244.

53 Idem, párrs. 245-255.

${ }^{54}$ Idem, párrs. 256-264.

55 Idem, párrs. 265-275. 
ció la especial relación de la Comunidad con el territorio reclamado ${ }^{56}$ y cuando declaró el territorio tradicional reclamado por la Comunidad como reserva natural privada, no aseguró la participación efectiva de los miembros de la Comunidad en la decisión ${ }^{57}$.

En cuanto al derecho a la vida, la Corte IDH señaló que la asistencia estatal brindada en materia de acceso y calidad de agua, alimentación, servicios de salud y educación no ha sido suficiente para superar las condiciones de especial vulnerabilidad en que se encuentra la Comunidad Xákmok Kásek. Consideró que esta situación está estrechamente vinculada a la falta de sus tierras, lo que derivó en la ausencia de posibilidades de autoabastecimiento y auto-sostenibilidad de los miembros de la Comunidad de acuerdo a sus tradiciones ancestrales. Ello los llevó a depender casi exclusivamente de las acciones estatales y verse obligados a vivir de una forma no solamente distinta a sus pautas culturales, sino en la miseria ${ }^{58}$.

Relacionado con lo anterior, en lo respectivo a los derechos de los nińos y nińas de la Comunidad, la Corte IDH sentenció que las condiciones de extrema vulnerabilidad en la que se encontraba la Comunidad afectaron en forma particular el desarrollo de estos, ocasionándoles altos índices de desnutrición. Igualmente, señaló que la mayoría de las personas cuya muerte fue imputable al Estado, debido a su negligencia, eran nińos o niñas. Adicionalmente, consideró que la pérdida de prácticas tradicionales y los perjuicios derivados de la falta de territorio, afectaron en forma particular el desarrollo e identidad cultural de los niños y niñas de la Comunidad ${ }^{59}$.

Finalmente, la Corte IDH resuelve condenar al Estado ${ }^{60}$, considerando que no adoptó las medidas suficientes y efectivas para garantizar sin discriminación los derechos de los miembros de la Comunidad, de conformidad con el 1.1. de la CADH, en relación con los derechos consagrados en los artículos 3 (Derecho al Reconocimiento de la Personalidad Jurídica), 4 (Derecho a la Vida), 8.1 (Garantías Judiciales), 19 (Derecho del Niño), 21 (Derecho a la Propiedad Privada) y 25 (Protección Judicial) de la CADH ${ }^{61}$.

\footnotetext{
${ }^{56}$ Para la Corte IDH la no restitución del territorio tradicional de la Comunidad afectó la identidad cultural de los miembros de la Comunidad, la cual corresponde a una forma de vida particular de ser, ver y actuar en el mundo, constituido a partir de su estrecha relación con sus tierras tradicionales y recursos naturales, no sólo por ser estos su principal medio de subsistencia, sino además porque constituyen un elemento integrante de su cosmovisión, religiosidad y, por ende, de su identidad cultural. Idem, párrs. 171-182.

${ }^{57}$ Idem, párrs. 86-170.

58 Véase, Clérico, L. y Aldao, M. "La igualdad como redistribución y reconocimiento: Derechos de los Pueblos Indígenas y Corte Interamericana de Derechos Humanos". Estudios Constitucionales, Vol. 19, n. ${ }^{o} 1$, 2011, pp. 157-198.

${ }^{59}$ Corte IDH. Comunidad Indígena Xákmok Kásek v. Paraguay, 24 de agosto 2010, Serie C Nº 214, párrs. 256264.

${ }^{60}$ Idem, párrs. 276-325.

${ }^{61}$ Idem, párr. 275.
} 


\subsection{Aspectos generales del caso del Pueblo Indígena Kichwa de Sarayaku v. Ecuador (2012)}

De forma similar al caso anterior, el caso del Pueblo Indigena Kichwa de Sarayaku se originó por el otorgamiento de una concesión para la exploración y explotación de hidrocarburos y petróleo en la región Amazónica de la Provincia de Pastasa, por parte de Estado ecuatoriano al Consorcio conformado por la Compañía General de Combustibles S.A. (CGC) y la empresa Petrolera Argentina San Jorge S.A (en adelante "el Consorcio"). El espacio territorial entregado en concesión, comprendía 200.000 hectáreas habitadas por varias comunidades y pueblos indígenas, dentro de ellas, el Pueblo Kichwa de Sarayaku, cuyo territorio ancestral y legal abarcaban un 65\% de los territorios otorgados en concesión a la empresa en cuestión.

La nacionalidad Kichwa la comparten dos Pueblos que poseen una misma tradición lingüística y cultural: El Pueblo Napo-Kichwa y el Pueblo Kichwa del Pastaza ${ }^{62}$. El Pueblo Sarayaku subsiste "de la agricultura familiar colectiva, la caza, la pesca y la recolección dentro de su territorio de acuerdo con sus tradiciones y costumbres ancestrales. Un promedio del $90 \%$ de sus necesidades alimenticias son satisfechas con productos provenientes de su propia tierra y el 10\% restante con bienes que provienen del exterior de la comunidad"63.

En el año 1992 el Estado adjudicó (reconoció) a favor del pueblo Sarayaku, a través del Instituto de Reforma Agraria y Colonización, de forma indivisa, una superficie aproximada de 135.000 hectáreas $^{64}$. En el año 1995 el Estado de Ecuador convocó a una licitación internacional para la exploración y explotación de hidrocarburos en el territorio nacional, dentro del cual se encontraba el que ocupaba ancestralmente el Pueblo Sarayaku. En el año 1996 se suscribe el contrato de exploración y explotación de hidrocarburos entre la Empresa Estatal de Petróleos del Ecuador y el Consorcio. Luego, el Consorcio le encomendó a otra empresa la realización de un plan de impacto ambiental para la prospección sísmica, el que fue realizado y aprobado por el Ministerio de Energía y Minería durante el año 1997. Sin embargo, el estudio no incluyó al pueblo Sarayaku, lo que no fue obstáculo para que el Consorcio desarrollara sus actividades de prospección sísmica hasta febrero de 2003.

Dentro de los hechos alegados como vulneraciones graves de los derechos humanos del Pueblo Sarayaku y sus integrantes, se encuentran los siguientes: (1) Entre los meses de

${ }^{62}$ Corte IDH, Pueblo Indigena Kichwa de Sarayaku v. Ecuador, 27 de junio de 2012, Serie C No 245, párrs. 51-53.

${ }^{63}$ Idem, párr. 52.

${ }^{64}$ Idem, párrs. 61-62. 
octubre de 2002 y febrero de 2003, la empresa avanzó un 29\% en su programación de trabajos, cargando 467 pozos con aproximadamente 1433 kilogramos de explosivos (pentolita) dentro del territorio ancestral de los Sarayaku; (2) El Consorcio destruyó un sitio de especial importancia en la vida espiritual de los miembros del Pueblo Sarayaku; (3) El Consorcio causó un gran impacto dentro del territorio y su subsistencia, ya que habilitó siete helipuertos, destruyó cuevas, fuentes de agua y ríos subterráneos; (4) Hubo amenazas, agresiones y hostigamientos a miembros del Pueblo Sarayaku por parte de trabajadores y empleados del Consorcio.

Así las cosas, el 26 de abril de 2010 la CIDH presentó ante la Corte IDH una demanda en contra del Estado ecuatoriano, por posible violación de los siguientes derechos de la CADH: (1) el derecho a la propiedad privada (artículo 21); (2) el derecho a la vida, las garantías judiciales y la protección judicial (artículos 4, 8 y 25, en relación con el artículo 1.1), en perjuicio del Pueblo y de sus miembros; (3) el derecho de circulación y residencia (artículo 22); (4) el derecho a la integridad personal (artículo 5) y (5) el deber de adoptar disposiciones de derecho interno (artículo $2{ }^{65}$.

Tal y como consta en la sentencia, el Estado de Ecuador, a través del Secretario de Asuntos Jurídicos del Presidente Rafael Correa y en el marco de una diligencia probatoria realizada por la Corte IDH al territorio del Pueblo Sarayaku, realizó un reconocimiento amplio y genérico de su responsabilidad internacional, el que junto con ser valorado por la Corte IDH, implicó “(...) una admisión de los hechos contenidos en el marco fáctico de la demanda de la Comisión, así como de los hechos pertinentes presentados por los representantes que los aclaren o expliquen. Asimismo, resalta el compromiso manifestado por el Estado relativo a impulsar las medidas de reparación necesarias en diálogo con el Pueblo Sarayaku. Todas estas acciones por parte del Ecuador constituyen una contribución positiva al desarrollo de este proceso, a la vigencia de los principios que inspiran la Convención y, en parte, a la satisfacción de las necesidades de reparación de las víctimas de violaciones de derechos humanos"66.

Lo anterior, simplificó la labor de adjudicación de la Corte IDH, procediendo a dictar sentencia y condenando al Estado ecuatoriano (por unanimidad) de responsabilidad internacional por la violación de los derechos humanos establecidos en el $\mathrm{CADH}$, en particular, de los derechos a la consulta, a la propiedad comunal indígena y a la identidad cultural ${ }^{67}$.

65 Ídem, párr. 3.

66 Ídem, párr. 27.

${ }^{67} \mathrm{La}$ Corte IDH en el presente caso establece, de forma muy precisa y con pretensiones generales, los deberes estatales con respecto a la "consulta indígena”. Además señala la vinculación existente entre la "consulta indígena” y los derechos de propiedad comunal y a la identidad cultural. Véase: Ídem, párrs. 145-220. 


\subsection{Nuevas perspectivas de los derechos de los grupos en la Corte IDH}

\subsubsection{Conceptualización realizada de los derechos de los grupos por la Corte IDH en casos anteriores}

La Corte IDH previamente a la resolución de los casos reseñados, dictó sentencia en tres casos donde se pronunció sobre la propiedad comunitaria indígena ${ }^{68}$. En los casos anteriores, en primer lugar la Corte IDH determinó que las violaciones de derechos humanos establecidos en la $\mathrm{CADH}$ ocurrieron con respecto a los miembros de las comunidades, sin señalar a la comunidad como tal, negándoles la subjetividad jurídica internacional en dicho ámbito.

En segundo lugar, en cuanto al contenido de la propiedad comunitaria indígena, en el caso de la Comunidad Indígena Yakye Axa v. Paraguay, la Corte IDH aclara su visión sobre lo colectivo de la propiedad indígena, señalando que ella puede "tener una significación colectiva, en el sentido de que el ejercicio de ésta no se centra en un individuo sino en el grupo y su comunidad ${ }^{69}$.

En este punto se ve una diferencia con la conceptualización de la propiedad colectiva indígena que hace la CIDH. Para la Corte IDH el derecho a la propiedad territorial es un derecho cuyos titulares son las personas individuales que conforman los pueblos indígenas o tribales, y cuyo ejercicio se desenvuelve en sistemas de propiedad colectiva. En cambio, para la CIDH el derecho a la propiedad de los pueblos indígenas y tribales es un derecho colectivo, cuyo titular es el pueblo correspondiente, el que a su vez ejercita en todo o en parte grupalmente ${ }^{70}$.

\subsubsection{Sobre la determinación de la Comunidad Indígena Xákmok Kásek}

Al analizar la determinación que hizo la Corte IDH sobre la Comunidad Indígena Xákmok Kásek, en conformidad con los presupuestos teóricos ya vistos en el apartado primero del presente trabajo y, en particular, según los planteamientos de Rodríguez Abascal, los principales problemas teóricos de los derechos de los grupos se encuentran en el plano práctico y, en concreto, en la determinación del grupo como sujeto de

${ }^{68}$ Estos casos son: Comunidad Mayagna (Sumo) Awas Tingni v. Nicaragua (2000); Comunidad Indigena Yakye Axa v. Paraguay (2005); Comunidad Indigena Sawhoyamaxa v. Paraguay (2006).

${ }^{69}$ Corte IDH. Comunidad Indígena Yakye Axa v. Paraguay, 17 de junio 2005, Serie C No 125, párr. 135.

${ }^{70}$ Véase, CIDH. Derechos de los Pueblos Indigenas y Tribales sobre sus tierras ancestrales y recursos naturales. OEA/ Ser. L/V/II. Doc. 56/09, 2009, p. 25. Sobre las consecuencias teóricas y jurídicas de ello, véase, Gajardo FALCón, op. cit., pp. 164-170. 
derechos. Es interesante este punto, ya que en el caso precitado la Corte IDH se tuvo que enfrentar al problema de determinación de la Comunidad. Según los alegatos del Estado las contradicciones encontradas en la denominación y pertenencia étnica de la Comunidad, impedirían la titulación de tierras a su favor y no se adecuaría "a las prescripciones del Estatuto Indígena y a la normativa internacional”. Para la Corte IDH, la Comunidad tiene una composición multiétnica, en la cual sus miembros se autoidentifican $^{71}$.

Para la Corte IDH, "[l]a identificación de la Comunidad, desde su nombre hasta su composición, es un hecho histórico social que hace parte de su autonomía. Este ha sido el criterio del Tribunal en similares situaciones. Por tanto, la Corte y el Estado deben limitarse a respetar las determinaciones que en este sentido presente la Comunidad, es decir, la forma cómo ésta se auto-identifique"72.

Avanzando en una nueva caracterización de los derechos de los grupos por parte de la Corte IDH, cobra importancia este punto, ya que junto con tener que determinar a la Comunidad, señaló que el reclamo de restitución de tierras, es decir, el derecho a la propiedad comunitaria indígena, lo realiza la Comunidad ${ }^{73}$ y sus miembros. Concordante con ello, al momento de establecer las medidas de reparación, señala a la Comunidad como destinataria de dichas medidas. En ese sentido, la Corte IDH en el punto resolutivo número 26 de la sentencia, señaló que: "El Estado deberá adoptar inmediatamente las medidas necesarias para que el Decreto N.o 11.804 que declaró como área silvestre protegida a parte del territorio reclamado por la Comunidad no sea un obstáculo para la devolución de las tierras tradicionales, de conformidad con lo expuesto en los párrafos 311 y 313 de esta Sentencia”. De forma similar, en el caso del Pueblo Kichwa, la Corte IDH determinó que dicha entidad era la parte lesionada y, por ende, el destinatario de las reparaciones que ordenó ${ }^{74}$.

\subsubsection{Del voto concurrente del Juez Eduardo Vio Grossi en el caso Xákmok Kásek al caso del Pueblo Indígena Kichwa de Sarayaku}

El Juez de la Corte IDH Eduardo Vio Grossi en el voto concurrente de la sentencia del caso Xákmok Kásek señaló que el fallo se inserta en una dirección que considera ajustada a derecho y justicia, y es acorde al desarrollo progresivo del Derecho Internacional de los Pueblos Indígenas ${ }^{75}$. El fallo abre una nueva perspectiva y permitiría arribar a una

${ }^{71}$ Corte IDH, Comunidad Indígena Xákmok Kásek v. Paraguay, 24 de agosto 2010, Serie C Nº 214, párrs. 34-50.

${ }^{72}$ Idem, párr. 37.

${ }^{73}$ Idem, párrs. 64-79.

${ }^{74}$ CorTe IDH, Pueblo Indígena Kichwa de Sarayaku v. Ecuador, 27 de junio de 2012, Serie C Nº 245, párr. 284.

75 En el voto concurrente el Juez Vio Grossi argumenta que el desarrollo progresivo del Derecho Internacional 
comprensión más amplia de lo dispuesto en el artículo 1 de la $\mathrm{CADH}$, "en orden a que la obligación de respetar y garantizar a toda persona el ejercicio de los derechos consagrados por ella incluiría también a las colectividades o comunidades, como los pueblos indígenas, en la medida que a tales entidades se les reconozca al menos algunos de esos derechos, los que, por ende, sus miembros únicamente podrían disfrutar y ejercer por su intermedio y en razón de que forman parte de la misma, lo que, en definitiva implicaría que no serían únicamente de carácter individual"76.

Para el Juez Vio Grossi esta nueva perspectiva se abre paso. La sentencia en comento, no sólo considera como víctimas del caso a los miembros de la Comunidad, también reconoce que es la Comunidad el sujeto que reclama la protección de sus derechos al territorio y la propiedad comunitaria que le correspondería. Además, el fallo menciona expresamente a la Comunidad como beneficiaria de las medidas que decreta. Argumentó, que la Corte IDH sin alejarse de su posición tradicional, parecería dejar margen para que en el futuro pudiese disponer de la posibilidad de adoptar una nueva aproximación en la materia y, particularmente, cuando en la sentencia se señala que "ha considerado que la estrecha vinculación de los pueblos indígenas con sus tierras tradicionales y los recursos naturales ligados a su cultura que ahí se encuentren, así como los elementos incorporales que se desprendan de ellos, deben ser salvaguardados por el artículo 21 de la Convención Americana"77.

Coincidimos con el Juez Vio Grossi en el punto anterior. La fundamentación que entrega la Corte IDH en el párrafo precitado sobre la propiedad comunitaria indígena abre una perspectiva interesante al respecto, ya que transforma los elementos culturales y las características propias de ella, en elementos que formarían parte del contenido esencial de la propiedad que protege el artículo 21 de la CADH. Así, la forma de ejercicio de la propiedad comunitaria y su titularidad, se volverían en elementos interdependientes, que no se podrían separar de la misma.

Concluye el voto concurrente el Juez Vio Grossi, señalando que en concordancia con el desarrollo progresivo del Derecho Internacional de los Derechos Humanos, sería aconsejable incluir en el concepto de "persona" contenida en diversos artículos de la $\mathrm{CADH}$ y en el concepto de "víctima", no sólo a los miembros de las comunidades indígenas individualmente considerados, sino que también a las comunidades como entes propios,

de los Derechos Humanos de los Pueblos Indígenas, reconoce a los pueblos como titulares de derechos, es decir, les reconoce derecho como grupo en su condición de tales. Para argumentar éste punto, cita una serie de resoluciones de organizaciones internacionales, véase, CoRTe IDH, Comunidad Indígena Xákmok Kásek v. Paraguay, 24 de agosto 2010, Serie C N² 214, voto concurrente Juez Eduardo Vio Grossi, párrs. 16-22.

${ }^{76}$ Ídem, párr. 25.

${ }^{77}$ Idem, párrs. 7-8. 
ubicándose la jurisprudencia de la Corte IDH en la tendencia moderna del Derecho Internacional de los Derechos Humanos ${ }^{78}$.

Como se puede apreciar, el voto concurrente del Juez Vio Grossi nos indica los principales aspectos de la nueva perspectiva que eventualmente podría comenzar en la jurisprudencia de la Corte IDH, sobre los derechos de los grupos de los pueblos indígenas en el sistema. La Corte IDH se abre a la posibilidad de entender los derechos de los grupos de forma complementaria a los derechos individuales de los miembros de las comunidades.

La perspectiva que entrega el Juez Vio Grossi en su voto concurrente se encuentra recogida en el fallo del Pueblo Kichwa de Sarayaku, de forma clara. La Corte IDH señala al respecto que " $[\mathrm{e}] \mathrm{n}$ anteriores oportunidades, en casos relativos a comunidades o pueblos indígenas y tribales el Tribunal ha declarado violaciones en perjuicio de los integrantes o miembros de las comunidades y pueblos indígenas o tribales. Sin embargo, la normativa internacional relativa a pueblos y comunidades indígenas o tribales reconoce derechos a los pueblos como sujetos colectivos del Derecho Internacional y no únicamente a sus miembros. Puesto que los pueblos y comunidades indígenas o tribales, cohesionados por sus particulares formas de vida e identidad, ejercen algunos derechos reconocidos por la Convención desde una dimensión colectiva, la Corte señala que las consideraciones de derecho expresadas o vertidas en la presente Sentencia deben entenderse desde dicha perspectiva colectiva" 79 .

\section{Conclusiones}

Con la revisión teórica damos cuenta de las dificultades que han tenido los derechos de los grupos para la teoría del derecho y en particular para la doctrina liberal, que los visualiza con bastante escepticismo. Sin embargo, posturas como las de Neus Torbisco y Rodríguez Abascal sirven para comprender que estos no sólo son compatibles con los derechos humanos, sino que en algunos casos (como en los casos revisados) son necesarios para complementar los individuales y generar las condiciones para el real respeto de los miembros de los grupos respectivos.

Aplicando el marco teórico propuesto en el apartado primero, es posible constatar que los problemas prácticos que plantea Rodríguez Abascal a los derechos de los grupos, en el caso de la Comunidad Xákmok Kásek, no fueron tales. Se puede evidenciar, que

78 Idem, párr. 26.

79 Corte IDH, Pueblo Indigena Kichwa de Sarayaku v. Ecuador, 27 de junio de 2012, Serie C N²45, párr. 231. 
los problemas que tienen los derechos de los grupos para volverse una realidad dentro de la jurisprudencia de la Corte IDH, son principalmente en lo que dice relación a la conceptualización de víctima y la atribución de intersubjetividad a los pueblos -como tales- por parte de la Corte IDH.

Para lo anterior, en la sentencia del caso Xákmok Kásek v. Paraguay se pueden encontrar los elementos teóricos suficientes para una nueva perspectiva de los derechos de los grupos en la jurisprudencia de la Corte IDH, siendo fundamental lo señalado por el Juez Vio Grossi en el voto concurrente de la misma, principalmente, lo concerniente a la tendencia moderna del Derecho Internacional de los Derechos Humanos. Dicha perspectiva se ve recogida, de forma breve pero clara, en el fallo de la Corte IDH en el caso del Pueblo Indigena Kichwa de Sarayaku.

El reconocimiento y protección de los derechos de grupo, que hemos identificado, es una base para salvaguardar la autonomía de las Comunidades y los individuos que las conforman. Incluso, tal como reconoció la Corte IDH en los casos analizados, una posible violación a la propiedad comunitaria indígena, puede atentar gravemente el derecho a la vida e integridad física de los individuos que componen los pueblos indígenas.

Así las cosas, los derechos de grupo en contextos multiculturales de fuente indígena pueden ser conceptualizados como derechos humanos que no sustituyen o anulan los derechos individuales, sino que los complementan e incluso pueden ser la base para el ejercicio del derecho a la vida, honrando con ello valores básicos en los que se fundamentan los derechos humanos, como la autonomía, igualdad y justicia. 